\title{
BEHAVIOUR OF SEMI-RIGID STEEL FRAMES WITH STEEL PLATE SHEAR WALLS
}

\author{
J.G. Yu ${ }^{1, *}$ and J.P. Hao ${ }^{2}$ \\ ${ }^{1}$ Associate Professor, Department of Civil Engineering, \\ $X i$ 'an University of Architecture and Technology, Xi'an, China \\ ${ }^{2}$ Professor, Department of Civil Engineering, \\ $X i$ 'an University of Architecture and Technology, Xi'an, China \\ *(Corresponding author: E-mail: yjggordon@163.com)
}

Received: 17 February 2015; Revised: 7 May 2015; Accepted: 28 July 2015

\begin{abstract}
This paper describes an investigation on the seismic behaviour of a new lateral resistance system which combines semi-rigid steel frames (SRSFs) with steel plate shear walls (SPSWs). A laboratory test, including two 1/3-scale one-bay, two-storey SRSFs with SPSWs, was conducted to study the influence of the stiffeners on SPSWs and the stiffness of beam-column connections. The results indicate that the new system inherits the merits both of SRSFs and SPSWs. It exhibits excellent seismic performance in terms of load carrying capacity, ductility, stiffness and energy dissipation. The stiffeners on SPSWs not only effectively reduce the forces taken by beams and columns but also improve the overall cyclic performance of structural systems. Moreover, they increase the initial stiffness and buckling load capacity of SPSWs especially. Further, the finite element analysis method was adopted for parametric study of the influence of connection stiffness and stiffener rigidity on the behaviour of SRSF-SPSW. It demonstrates that the SPSW in the proposed structural system undertakes $70 \%-80 \%$ of overall lateral load. The influence of connection stiffness on the load carrying capacity depends on the stiffness of columns and thickness of infill plates. This influence is enlarged with increasing stiffness of columns and reducing thickness of infill plates. The load carrying capacity of a structural system is increased by $42.2 \%$ when connections are changed from pin to rigid. Generally, this research provides a basis for engineering application and theoretical analysis of the SRSF-SPSW structural system.
\end{abstract}

Keywords: Steel frame, Semi-rigid connection, Steel plate shear wall, Seismic behavior, Beam-column connection stiffness, Nonlinear finite element analysis

DOI: 10.18057/IJASC.2016.12.2.5

\section{INTRODUCTION}

Steel plate shear walls (SPSWs) have many advantages, including high initial lateral stiffness, stable hysteresis behaviour and good energy dissipation as evidenced by a series of analytical and experimental studies at the University of Alberta [1]. Many experimental studies on single or multi-storey SPSWs were performed to assess the influence of design parameters [2]-[12]. Parts of the experimental investigations are summarized in Table 1. Tsai and Li [7], Alinia and Dastfan [13], Alavi and Nateghi [14] and Nie et al. [15] further investigated SPSWs with various types of stiffener, including longitudinal stiffener, transverse stiffener, cross stiffener, diagonal stiffener, vertical and horizontal ribbed stiffener, etc.

In the traditional analysis and design of steel frames, beam-column connections are often assumed to be rigid or pinned. However, beam-column connections in a structure normally lie in between the above-mentioned two conditions. It is reasonable to consider them as semi-rigid connections in the design of steel frames. The seismic behaviour of steel frames with semi-rigid beam-column connections has been widely studied in the past [16]-[20]. Azizinamini and Radziminski [16], Elnashai and Elghazouli [17] and Kishi et al. [18] verified that semi-rigid frames possess excellent ductility and stable hysteretic behaviour. Bernuzzi et al. [19] demonstrated that semi-rigid 
connections have adequate energy dissipation capacity. Nevertheless, low stiffness and a nonlinear response of semi-rigid connection restrain the application of this structural system. For instance, semi-rigid connections weaken overall stability of structures, especially at large drift ratio [20]. Therefore, it is beneficial to enhance the lateral stiffness of semi-rigid steel frames (SRSFs).

A new structural system taking advantage of SRSFs and SPSWs is proposed in this study. Incorporation of SPSWs in a SRSF can alleviate its ductility requirements in beam-column connections as well as improve the mechanical behaviour of connections, increase stiffness and energy dissipation of the structural system, and realize multi-failure criteria [21]. Beam-column connections are normally designed as rigid ones in most tests and analysis of the SPSW system. SPSW systems with hinged connections or with consideration of connection stiffness are analyzed only in a few studies. Caccese et al. [22] tested six unstiffened thin SPSW specimens with moment-resisting connections or shear connections. The test results indicated that initial stiffness of beam-column connections had little influence on the overall behaviour of the SPSW system. However, Kulak et al. [23] pointed out that the overall behaviour of the SPSW system is affected by lots of factors, such as material properties, welding cracks and geometric defect. In addition, Xue [24] and Alinia and Dastfan [25] also concluded that beam-column connections had no obvious influence on the overall behaviour of SPSWs based on finite element studies. Nowadays, the influence of beam-column connections on the behaviour of SPSWs is still debatable. More investigation of SPSW with different beam-column connections is needed.

Table 1. Summary of tests on SPSWs

\begin{tabular}{cccccc}
\hline Reference & Specimen & Scale & Depth-width ratio & Height-thickness ratio & Column flexibility factor \\
\hline Lubell and Prion [2] & SPSW2 & $1: 4$ & 1.00 & 549 & 3.35 \\
Chen and Guo [3] & - & $1: 3$ & 1.00 & 273 & 2.52 \\
& - & $1: 3$ & 1.00 & 170 & 2.28 \\
Wang [4] & H1, H2 & $1: 3$ & 1.28 & 363 & 2.79 \\
Lin and Tsai [5] & F1, F2 & $1: 3$ & 1.28 & 363 & 2.12 \\
& S & $1: 2$ & 0.50 & 511 & 1.01 \\
Park et al [6] & SC2T & $1: 3$ & 0.68 & 500 & 1.24 \\
& SC4T & $1: 3$ & 0.68 & 250 & 1.44 \\
Tsai and Li [7] & SC5T & $1: 3$ & 0.68 & 167 & 2.58 \\
Qu and Bruneau [8] & SPSW N & $1: 1$ & 1.52 & 1144 & 3.01 \\
\hline
\end{tabular}

This paper systematically studies the influences of connection stiffness on the behaviour of SPSWs and examines the seismic behaviour of the SRSF-SPSW structural system. In addition, explanations for insignificant influence of beam-column connection on the overall behaviour of the SPSW system are addressed. This is mainly attributed to the fact that large column flexibility of specimens dominates the overall behaviour of the SPSW system. In this paper, the seismic behaviour of the SRSF-SPSW structural system is investigated through experimental and numerical studies. Two one-bay, two-storey SRSF-SPSWs were tested under constant axial loading and lateral cyclic loading. Steel plates with and without stiffeners and stiffness of beam-column connections were compared in the test. In addition to experimental study, a nonlinear finite element analysis was performed for parametric study. It estimated the influence of connection stiffness and stiffener rigidity of SPSWs on the seismic behaviour of the structural system. 


\section{EXPERIMENTAL PROGRAMME}

\subsection{Specimens}

A one-bay, two-storey frame was designed to represent the bottom two floors of a frame-shear wall structure. Two specimens namely HAC and HPP were differentiated by beam-column connection and stiffeners on SPSWs. Details of the specimens are shown in Figure 1. The span of the specimen was $1350 \mathrm{~mm}$ and the height was $2750 \mathrm{~mm}$. The cross-sections of the bottom beam, intermediate beam and top beam were $\mathrm{H} 410 \times 350 \times 12 \times 25, \mathrm{H} 200 \times 100 \times 5.5 \times 8$ and $\mathrm{H} 300 \times 150 \times 6.5 \times 9$, respectively. Both columns had cross-sections of H150 $150 \times 7 \times 10$. L $140 \times 90 \times 8$ was adopted for the top and seat angle while L70 $\times 8$ was used for the web angle in the semi-rigid connection. The thickness of the infill steel plate was $4 \mathrm{~mm}$. Steel plates with $40 \mathrm{~mm}$ depth and $4 \mathrm{~mm}$ thick were used for stiffeners. The infill plates were welded to the columns and the beams by fish plates. Semi-rigid beam-column connections were adopted in both specimens. Top and intermediate beam-column connections were identified as HAC-T and HAC-M in specimen HAC (or HPP-T and HPP-M in specimen HPP), respectively. The details of beam-column connections are shown in Figure 2.

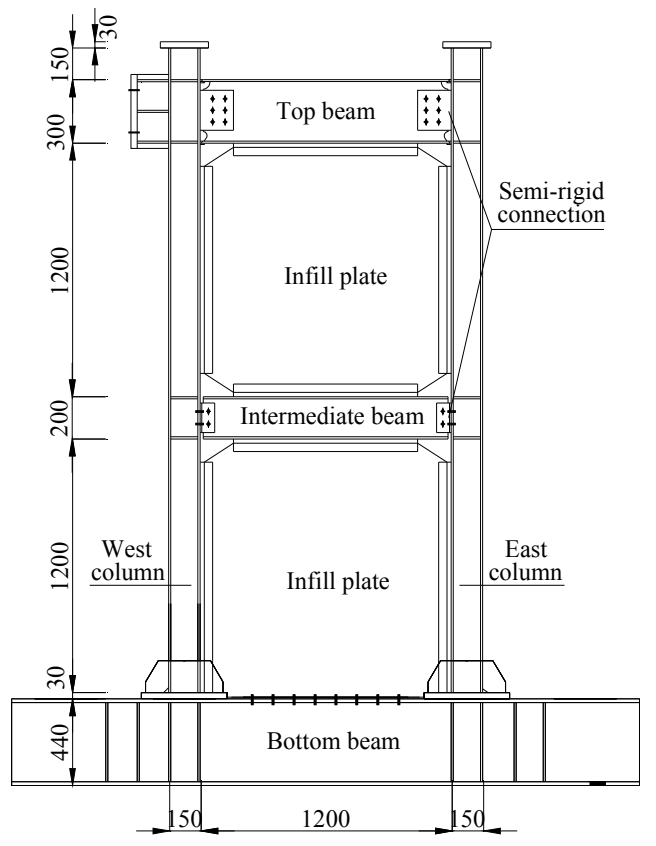

(a) Specimen HAC

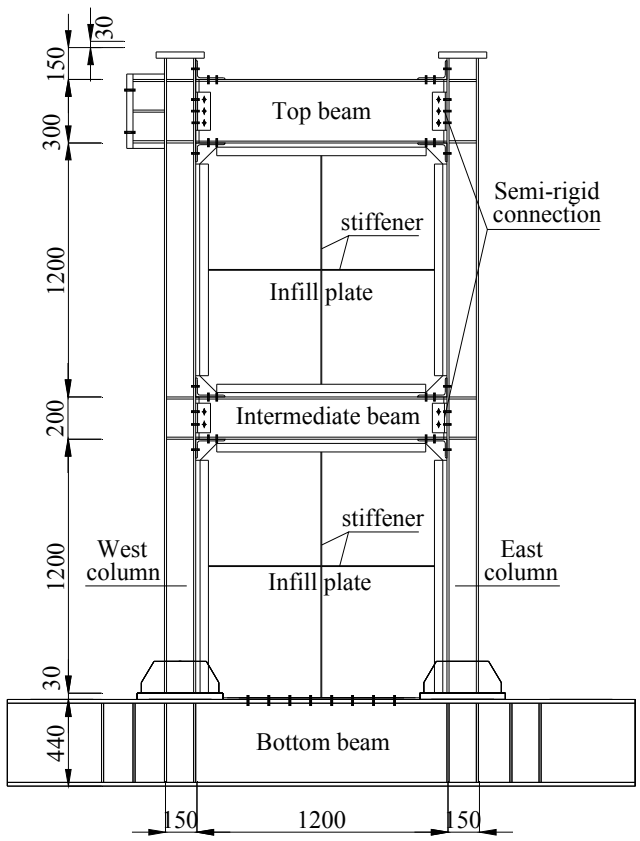

(b) Specimen HPP

Figure 1. Details of the Specimens

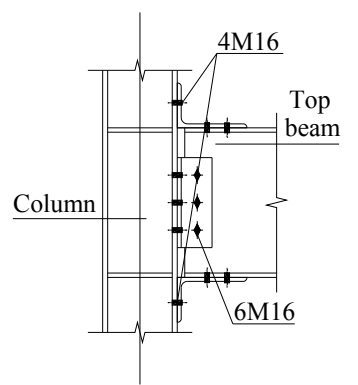

(a) HAC-T

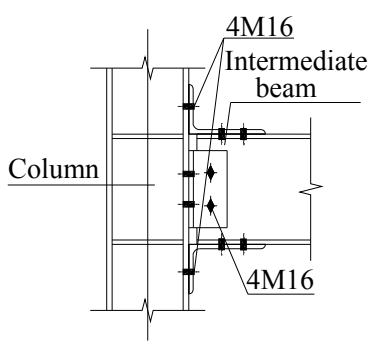

(b) HAC-M

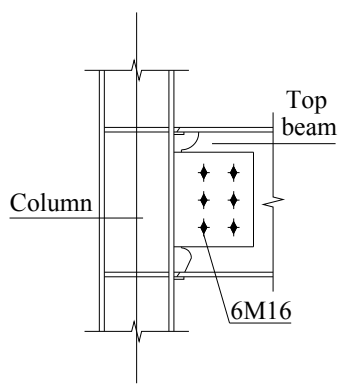

(c) HPP-T

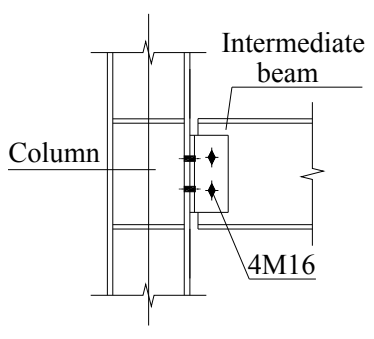

(d) HPP-M

Figure 2. Details of the Semi-rigid Connections 
The model scale was about 1/3. The specimens were built using Q235 steel which has a characteristic yield strength of $235 \mathrm{~N} / \mathrm{mm}^{2}$. A material property test was conducted according to Chinese national standards "Metallic materials-Tensile testing at ambient temperature (GB/T228-2002)" [27] and "Steel and steel products-Location and preparation of test pieces for mechanic testing (GB/T 2975-1998)" [26]. The material properties of each component are shown in Table 2.

Table 2. Material Properties

\begin{tabular}{ccccc}
\hline Member & $\begin{array}{c}\text { Yield stress } \\
\mathrm{f}_{\mathrm{y}}\left(\mathrm{N} / \mathrm{mm}^{2}\right)\end{array}$ & $\begin{array}{c}\text { Ultimate stress } \\
\mathrm{f}_{\mathrm{u}}\left(\mathrm{N} / \mathrm{mm}^{2}\right)\end{array}$ & $\begin{array}{c}\text { Elongation } \\
(\%)\end{array}$ & $\begin{array}{c}\text { Elastic modulus } \\
\mathrm{E}\left(10^{5} \mathrm{~N} / \mathrm{mm}^{2}\right)\end{array}$ \\
\hline $\mathrm{H} 300 \times 150 \times 6.5 \times 9$ & 275.67 & 445.33 & 27.70 & 2.16 \\
$\mathrm{H} 200 \times 100 \times 5.5 \times 8$ & 314.77 & 455.47 & 24.66 & 2.21 \\
$\mathrm{H} 150 \times 150 \times 7 \times 10$ & 269.33 & 428.23 & 21.16 & 2.00 \\
4.0 mm steel plate & 356.50 & 515.53 & 22.59 & 2.15 \\
L70 $\times 8$ & 353.31 & 461.62 & 19.06 & 2.10 \\
L140 $\times 90 \times 8$ & 284.60 & 424.20 & 22.20 & 2.10 \\
\hline
\end{tabular}

\subsection{Test Setup, Loading Sequence and Instrumentation}

The test setup for the specimen is shown in Figure 3. The tests were conducted in the Structural Engineering Research Laboratory at Xi'an University of Architecture and Technology. The specimens were fixed on the strong floor through high strength steel rods. A reaction beam was established for applying axial load. A lateral support system was established for restraining out-of-plane movement of the specimen. Vertical constant axial loading was applied by two 2000 $\mathrm{kN}$ jacks while lateral loading was applied by a two-direction $1000 \mathrm{kN}$ MTS hydraulic actuator. To study the overall connection performance of the structure, the arrangement of displacement transducers was as shown in Figure 4.

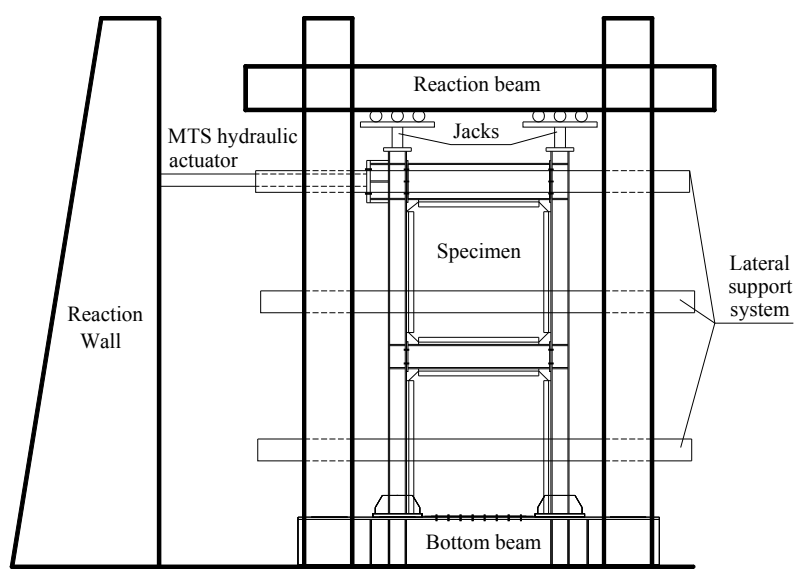

Figure 3. Test Setup

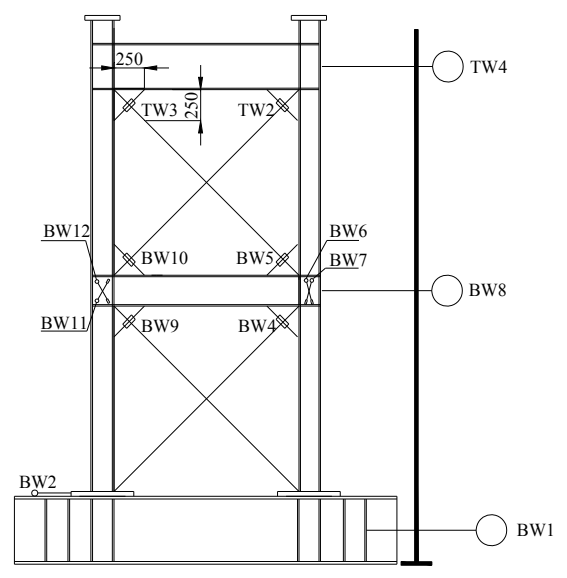

Figure 4. Displacement Transducers Configuration

The loading sequence for testing the specimen was determined according to provisions in "Specification of Testing Methods for Earthquake Resistant Building (JGJ 101-96)" [28]. In order to study the behaviour of SPSWs with pre-compressed frame columns, vertical constant axial loading was first applied on the top of the columns at $200 \mathrm{kN}$. In the second stage of loading, lateral cyclic loading was applied along the centre line of the top beam. It was noted that only one concentrated load was considered due to the limitation of the test setup. Lateral loading was applied in two steps: loading control in the elastic stage and displacement control after yield. Yield displacement was determined based on the load-displacement response to check strains of steel at critical sections (e.g. the top and bottom of column). Subsequently, lateral displacement was 
applied at $1,1.5,2,2.5, \ldots 0.5 \mathrm{n}$ times of yield displacement and was repeated three times at each specific displacement. The test was stopped when the lateral displacement reached the maximum deformation at $\mathrm{H} / 50$, where $\mathrm{H}$ is the height of the specimen.

\section{EXPERIMENTAL RESULTS}

\subsection{General Behaviour}

\subsubsection{Specimen HPP}

The typical behaviour of specimen HPP during the test is shown in Figure 5. At the initial stage of loading, the infill plate in the first storey tended to buckle along the diagonal direction when lateral load reached $300 \mathrm{kN}$ while that remained elastic in the second storey. As a result, residual deformation of the infill plate in the first storey was observed. The specimen HPP yielded at a lateral load of $450 \mathrm{kN}$. Under this load, yielding displacement $\delta_{\mathrm{y}}$ was measured as $12 \mathrm{~mm}$. Subsequently, specimen HPP was tested under displacement control. At a lateral displacement of $1.5 \delta_{\mathrm{y}}$, tension straps were found in the infill plate in the first storey while buckling in the flange of the first storey east corner column was found as shown in Figure 5(a). As lateral displacement increased, crossed out-of-plane residual deformation of the infill plate in the first storey was found at a displacement of $2 \delta_{\mathrm{y}}$. Afterwards, the specimen reached the peak lateral load in the push direction at the first cycle of $2.5 \delta_{\mathrm{y}}$ displacement. The east column in the first storey exhibited out-of-plane bending as shown in Figure 5(b). As displacement reversed, the infill plate in the first storey fractured at the west upper corner as shown in Figure 5(c). Meanwhile, the infill plate in the second storey remained elastic. The specimen reached peak lateral load in the pull direction at the first cycle of $3 \delta_{\mathrm{y}}$ displacement. The infill plate in the first storey cracked from the fish plate in the east upper direction. The east column exhibited out-of-plane bending while the west column had obvious concavities. At a displacement of $3.5 \delta_{\mathrm{y}}$, the column flange distorted in the west upper corner of the first storey and the infill plate in the first storey formed the first penetrating crack as shown in Figure 5(d). Beam-column connections rotated and the beam separated from the flange of columns with 1-3 mm as shown in Figure 5(e). At an advanced stage of loading, a tension field was formed in the infill plate in the second storey while diagonal " $\mathrm{X}$ "-shaped cracks occurred in the infill plate of the first storey. The test was stopped at a displacement of $4.5 \delta_{\mathrm{y}}$ when lateral loading decreased to approximately $80 \%$ of the peak lateral load. Cracks formed of about $4 \mathrm{~mm}$ wide between outside flanges of the columns and foots as shown in Figure 5(f), i.e., the specimen failed with plastic hinges in the columns. No deformation of the top beam-column connection was recorded throughout the test.

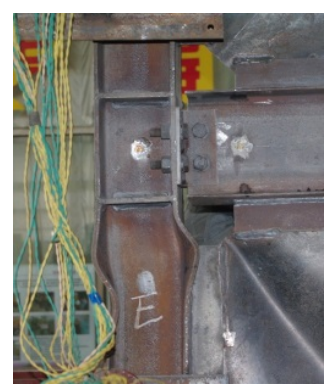

(a) Buckling of column flange

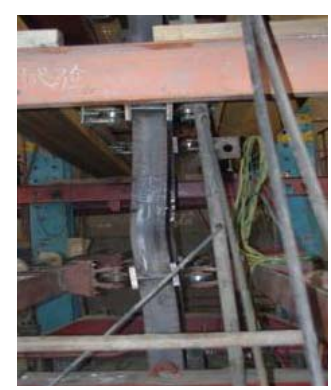

(b) Out-of-plane buckling of column

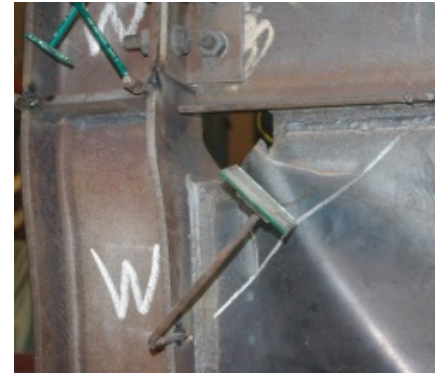

(c) Plate weld tearing 


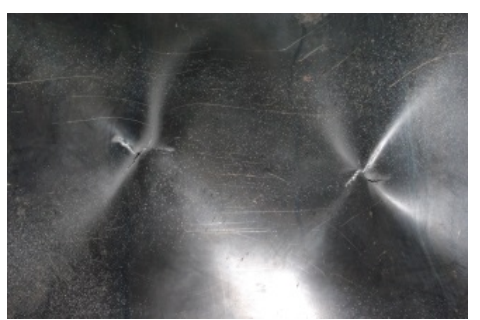

(d) Tearing of infill plate in the first story

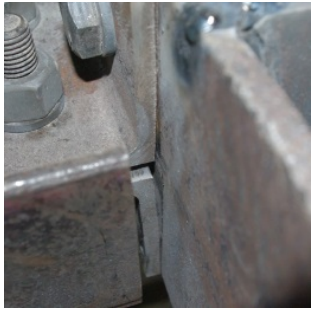

(e) Connection rotating

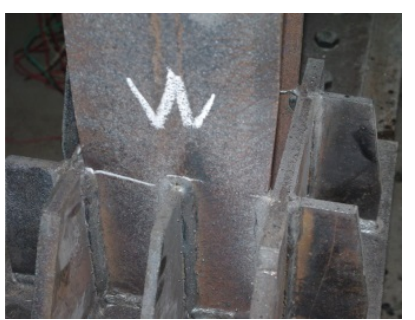

(f) Tearing at the column foot

Figure 5. Typical Behavior of Specimen HPP during the Test

\subsubsection{Specimen HAC}

The typical behaviour of specimen HAC during the test is shown in Figure 6. With the reinforce of stiffeners, buckling of the infill plate in the specimen HAC occurred at higher lateral loading compared with HPP. The infill plate in the first storey bulged slightly in the upper right region in the first cycle of $500 \mathrm{kN}$ lateral loading. Top and seat angles in the west top connection were opened and closed during the cyclic loading. The yield displacement for specimen HAC was 11.9 $\mathrm{mm}$ and the corresponding lateral load was $450.9 \mathrm{kN}$. The infill plate in the first storey buckled at the upper region in the first cycle of $1.5 \delta_{\mathrm{y}}$ displacement. Tension straps in both infill plates developed gradually while top and seat angles at the connections deformed with residual displacement. Buckling of the vertical stiffener occurred in the infill plate of the first storey at a displacement of $2.0 \delta_{\mathrm{y}}$. Local buckling at the west column induced fracture of the angle plate connecting the beam to the column as shown in Figure 6(a). As the purpose of the test was to investigate the effect of SPSWs on seismic performance of composite frames, the angle plate was replaced before continuing the test. At a displacement of $2.5 \delta_{\mathrm{y}}$, out-of-plane deformation of the infill plate was significant. Buckling of the infill plate reversed with a loud noise during the test. The column buckled at the inner flange below the intermediate beam while the welding of the west column to foot cracked. Meanwhile, welding of stiffeners in the top connection of the west column fractured. Subsequently, both columns buckled below the middle connections in the second cycle of $3.0 \delta_{\mathrm{y}}$ displacement as shown in Figure 6(b). Buckling of stiffeners in the first storey infill plate occurred at the third cycle of $3.0 \delta_{\mathrm{y}}$ displacement as shown in Figure 6(c). At an advanced stage of loading, the residual out-of-plane deformation of the first storey infill plate was about $8 \mathrm{~mm}$. The lateral load decreased significantly as welding of the west column cracked as shown in Figure 6(d). The test was stopped at $3.5 \delta_{\mathrm{y}}$ displacement when serious out-of-plane flexural and torsional buckling occurred for the specimen as shown in Figure 6(e).
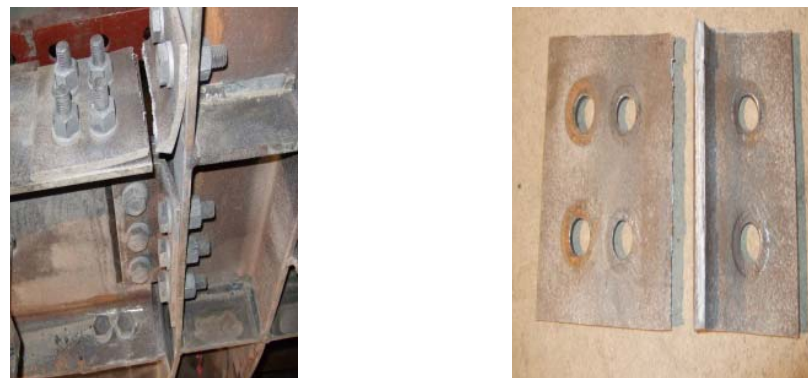

(a) Fracture of Angle Plate

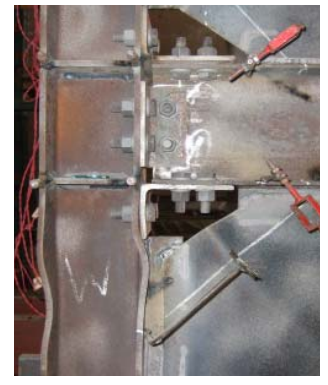

(b) Buckling of Column Flange 


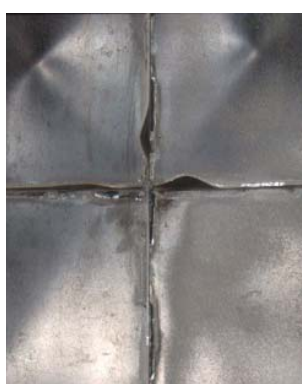

(c) Multi-buckling of stiffeners

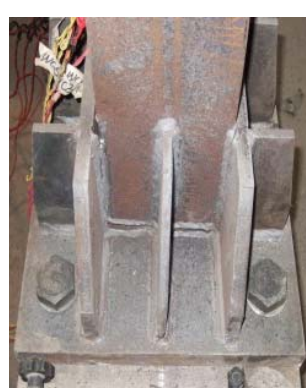

(d) Welds tearing at column foot

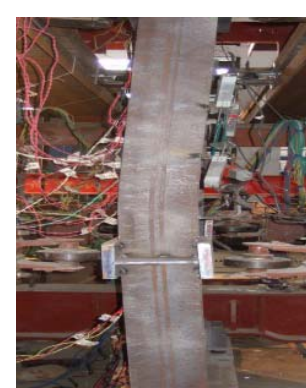

(e) Out-of-plane buckling of column

Figure 6. Typical Behavior of Specimen HAC during the Test

\subsection{Failure Modes}

The failure modes of the specimens are shown in Figure 7. Specimen HPP exhibited obvious tension straps in infill plates and local tearing at the intersection of tension straps. Plastic hinges formed at column-foot connections and under intermediate beam-column connections accompanied by buckling of the column and angle plate above the connections. Residual deformation of the upper infill plate was smaller than that of the bottom infill plate. For specimen HAC, multi-buckling of stiffeners occurred in both infill plates. However, stiffeners are effective to restrain out-of-plane deformation of the infill plate and to reduce the concavity of the columns. Similar to specimen HPP, plastic hinges formed at column-foot connections and under intermediate beam-column connections. The out-of-plane residual deformation was as much as $10 \mathrm{~mm}$ in the bottom infill plate. Bending and torsion out-of-plane deformation of the frame columns was significant. Three types of buckling in the stiffened SPSW were identified, including overall buckling, local buckling in the cell grids and relative buckling.

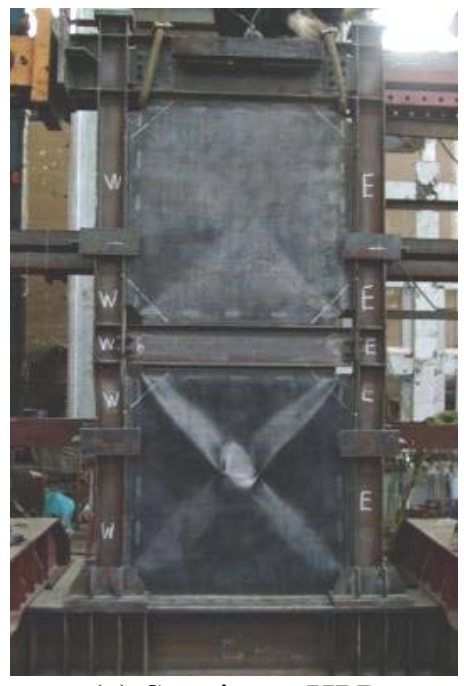

(a) Specimen HPP

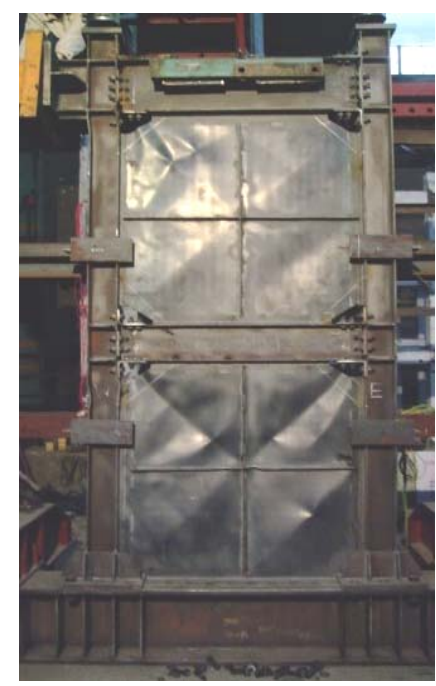

(b) Specimen HAC

Figure 7. Failure mode of test specimen

\subsection{Hysteresis Behaviour and Energy Dissipation}

The hysteresis behaviour in the lateral load-displacement relationships of specimens HPP and HAP are plotted in Figure 8. The pinching effect is more obvious in specimen HAC than that in specimen HPP. It demonstrates that incorporation of stiffeners on the infill plate is effective in enhancing the seismic performance of SPSWs. 
The energy dissipation of the specimens was computed from the area hysteretic loops at each cycle. The decomposition of energy dissipation at the first and second floors is given in Table 3. Energy dissipation of specimen HAC is higher than that in specimen HPP. This is attributed to the failure of specimen HPP being concentrated in the first floor. As a result, the second storey of the structural system seldom contributes to the dissipation of energy. The addition of stiffeners, which divided the thin steel plates, reduced the height-thickness ratio of the infill plates. This is of benefit for resisting lateral loads as well as delaying the buckling of infill plates. It means that the lateral stiffness is enhanced for the specimens and the capability of the two infill plates can be fully used.

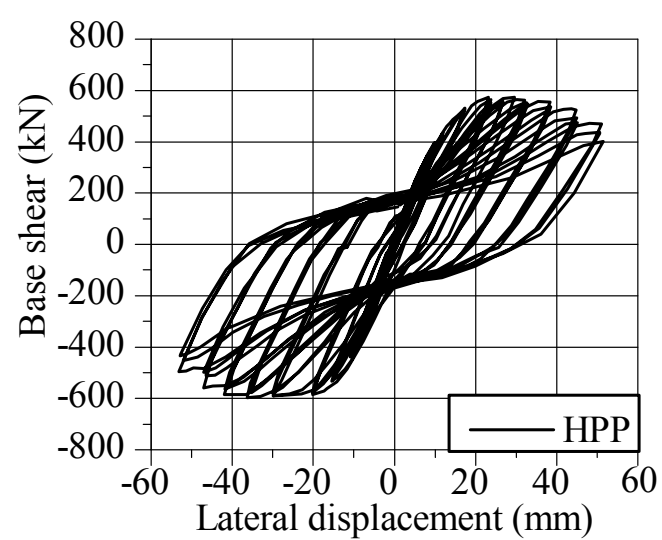

(a) Hysteresis curve of HPP

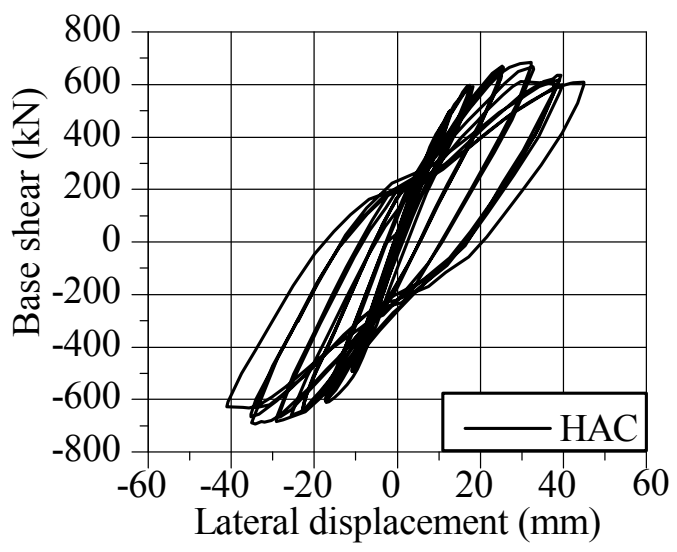

(b) Hysteresis curve of HAC

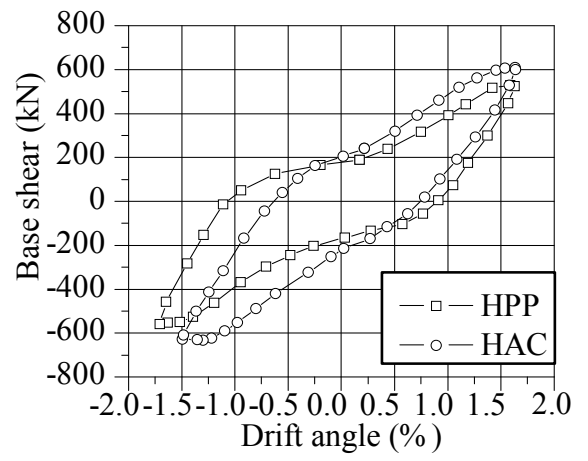

(c) Hysteresis curve of the two specimens at $1.6 \%$ drift

Figure 8. Load-displacement Hysteresis Curves

Table 3. Energy Dissipation of Specimens

\begin{tabular}{ccccccc}
\hline Loading & \multicolumn{3}{c}{ Specimen HPP } & \multicolumn{3}{c}{ Specimen HAC } \\
\cline { 2 - 7 } levels & Entirety & First story & Second story & Entirety & First story & Second story \\
\hline $100 \mathrm{kN}$ & 50 & 21 & 29 & 49 & 26 & 24 \\
$400 \mathrm{kN}$ & 736 & 368 & 367 & 2130 & 1486 & 643 \\
$1 \delta_{\mathrm{y}}$ & 1127 & 492 & 545 & 2416 & 1680 & 736 \\
$2 \delta_{\mathrm{y}}$ & 723 & 4526 & 2714 & 10263 & 5611 & 4652 \\
$3 \delta_{\mathrm{y}}$ & 17915 & 11969 & 5909 & 23711 & 12885 & 10826 \\
$3.5 \delta_{\mathrm{y}}$ & 23376 & 13767 & 7745 & 30437 & 16417 & 14021 \\
$4 \delta_{\mathrm{y}}$ & 29588 & 19250 & 10314 & \multicolumn{3}{c}{ Unit: kN·mm } \\
\hline
\end{tabular}




\subsection{Skeleton Curve}

A skeleton curve is a hysteresis curve which is the peak point of the first cycle connected at each loading level. The skeleton curves of specimens HPP and HAC are shown in Figure 9. A summary of test results is given in Table 4. Here, $\mathrm{P}_{\mathrm{y}}$ and $\mathrm{P}_{\max }$ are the yield load and peak load respectively; $\delta_{\mathrm{y}}$ is the yield displacement and $\delta_{\max }$ is defined as the displacement at peak load; $\delta_{u}$ is defined as the displacement when lateral loading decreased to $85 \%$ of the peak load; h represents the storey height. Ductility is defined as the ratio of ultimate displacement to yielding displacement, i.e. $\mu=\delta_{\mathrm{u}} / \delta_{\mathrm{y}}$, according to "Specification of Testing Methods for Earthquake Resistant Building (JGJ 101-96)" [28]. As depicted in Figure 10, the yield point $\left(\delta_{\mathrm{y}}, \mathrm{P}_{\mathrm{y}}\right)$ is determined through the concept of equal plastic energy. The area under the idealized elastic-plastic curve was equal to that of the actual pushover curve. The initial stiffness of the two specimens was almost the same. As seen in Table 4, the specimens did not exhibit symmetrical behaviour in the push and pull directions. Stiffness in the push direction was smaller than that in the pull direction. This may be attributed to other influential factors, such as the initial defects and strong column constraints in the loading side.

Installation of the stiffeners increased the stiffness and load carrying capacity of the specimen. Lateral stiffness, yield load, and peak load of the stiffened SPSW were approximately 1.06, 1.05, and 1.18 times that of the non-stiffened SPSW, respectively. The ductility coefficient of the non-stiffened SPSW was about 1.07 times that of the stiffened SPSW. It was illustrated that stiffened SPSWs have a higher lateral load carrying capacity but lower ductility as compared to non-stiffened SPSWs. It is worth noting that the SRSF-SPSW system possessed ductility of above 4.0, which demonstrated a good plastic deformation capacity.

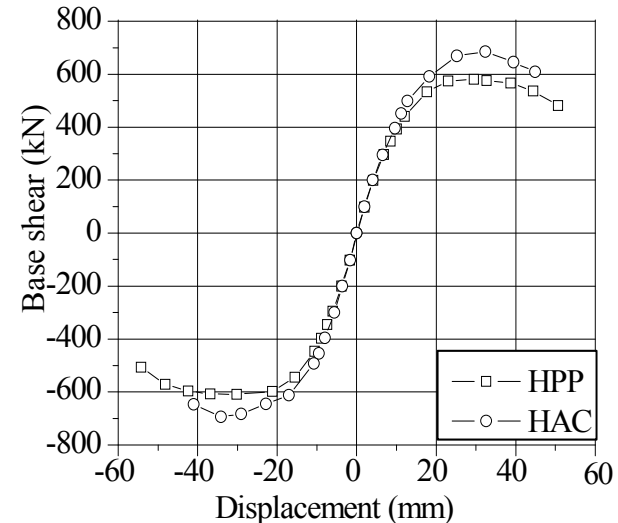

Figure 9. Load-displacement Envelope

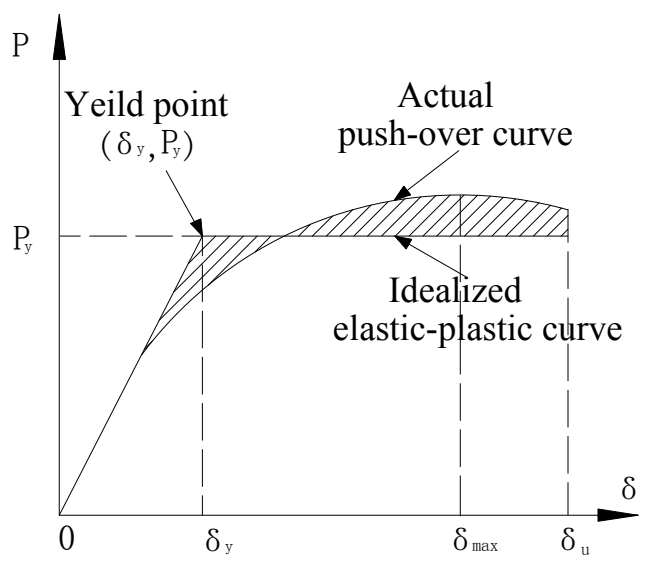

Figure 10. Definition of a Yield Point

Table 4. Summary of Test Results

\begin{tabular}{|c|c|c|c|c|c|c|c|c|c|c|c|}
\hline \multicolumn{2}{|c|}{ Specimen } & \multirow{2}{*}{$\begin{array}{c}\begin{array}{c}\text { Lateral } \\
\text { stiffness }\end{array} \\
\mathrm{P}_{\mathrm{y}} / \delta_{y} \\
(\mathrm{kN} / \mathrm{mm})\end{array}$} & \multicolumn{3}{|c|}{ Yielding load } & \multicolumn{3}{|c|}{ Peaking load } & \multicolumn{2}{|c|}{$\begin{array}{c}\text { Ultimate } \\
\text { displacement }\end{array}$} & \multirow{2}{*}{$\begin{array}{c}\begin{array}{c}\text { Ductility } \\
\text { coefficient }\end{array} \\
\mu\end{array}$} \\
\hline \multirow{4}{*}{$\mathrm{HAC}$} & Direction & & $\begin{array}{c}\mathrm{P}_{\mathrm{y}} \\
(\mathrm{kN})\end{array}$ & $\begin{array}{c}\delta_{y} \\
(\mathrm{~mm})\end{array}$ & $\delta_{y} / h$ & $\begin{array}{c}\mathrm{P}_{\mathrm{m}} \\
(\mathrm{kN})\end{array}$ & $\begin{array}{r}\delta_{\max } \\
(\mathrm{mm})\end{array}$ & $\begin{array}{c}\delta_{\max } \\
/ h\end{array}$ & $\begin{array}{c}\delta_{u} \\
(\mathrm{~mm})\end{array}$ & $\delta_{u} / h$ & \\
\hline & $\operatorname{Push}(+)$ & 36.00 & 450.0 & 12.50 & $1 / 220$ & 684.6 & 29.20 & $1 / 93$ & 44.92 & $1 / 61$ & 3.60 \\
\hline & Pull(-) & 40.08 & 451.7 & 11.27 & $1 / 244$ & 690.0 & 35.35 & $1 / 77$ & 46.49 & $1 / 59$ & 4.12 \\
\hline & Average & 37.89 & 450.9 & 11.90 & $1 / 232$ & 687.3 & 32.29 & $1 / 85$ & 45.71 & $1 / 60$ & 3.86 \\
\hline \multirow{3}{*}{ HPP } & $\operatorname{Push}(+)$ & 33.67 & 428.9 & 12.74 & $1 / 216$ & 574.43 & 23.15 & $1 / 118$ & 51.33 & $1 / 54$ & 4.03 \\
\hline & Pull(-) & 37.79 & 434.2 & 11.49 & $1 / 239$ & 596.04 & 36.37 & $1 / 75$ & 52.82 & $1 / 52$ & 4.60 \\
\hline & Average & 35.61 & 431.6 & 12.12 & $1 / 227$ & 585.23 & 29.76 & $1 / 92$ & 52.13 & $1 / 53$ & 4.32 \\
\hline
\end{tabular}




\subsection{Mechanical Analysis of the Semi-rigid Connections}

Dial gauges were installed (e.g. BW4, BW5, BW9, BW10, TW2 and TW3) at the end of the beams (as shown in Figure 4) to measure the load-rotation relationship of the beam-column connections. It aimed to investigate the interaction between semi-rigid connections and the SPSW. Based on the Pythagorean theorem, rotation $\alpha$ could be calculated with Equation (1).

$\alpha=\arccos \left[\frac{2 \times 250^{2}-(250 \sqrt{2}+d i s p)^{2}}{2 \times 250^{2}}\right]-\frac{\pi}{2}$

where, disp is the data tested by the dial gauges.

Load-rotation relationships at the ends of intermediate beams in both specimens are shown in Figure 11. In the elastic stage, data measured by two gauges could properly reflect the real condition of the connections. At the level of $1.0 \delta_{\mathrm{y}}$, the specimen was partly in plastic and out-of-plane deformation; the gauges at the connection were out of order. However, there was no obvious degradation tendency for the connection stiffness during the test. Development of plastic strain in the infill plates had limited impact on the performance of the connections. Comparing the stiffness degradation of the connections in both specimens, it could be illustrated that stiffness of the specimen HAC was approximately three times that of specimen HPP. Therefore, stiffened SPSWs could reduce the ductility requirement of the connections.

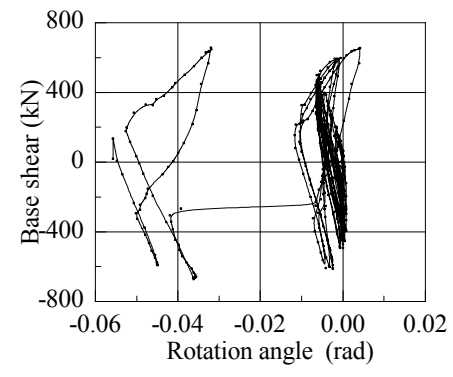

(a) HAC Up east (BW5)

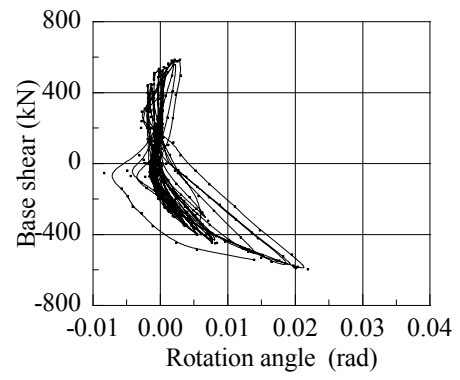

(c) HPP Up east (BW5)

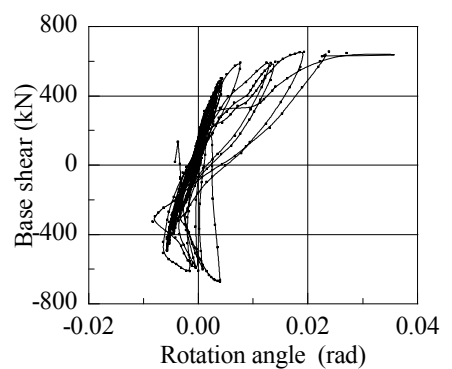

(b) HAC Up west (BW10)

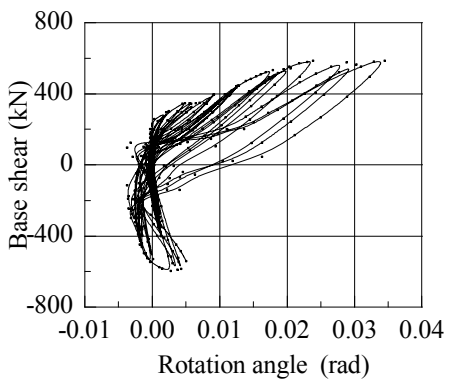

(d) HPP Up west (BW10)

Figure 11. Rotation Versus Load of Intermediate Beam 


\section{FINITE ELEMENT ANALYSIS}

\subsection{FE Model}

The nonlinear finite element models for tested specimens were built in the ANSYS package. The steel frames, infill plates and stiffeners were modelled using the Shell181 element. As beam-column connections were complex, a rigid plate combined with Combin39 element was adopted. The finite element model of the specimen is illustrated in Figure 12. The model had identical geometry, boundary conditions, material properties and loading sequence as the specimens in the experimental investigation.

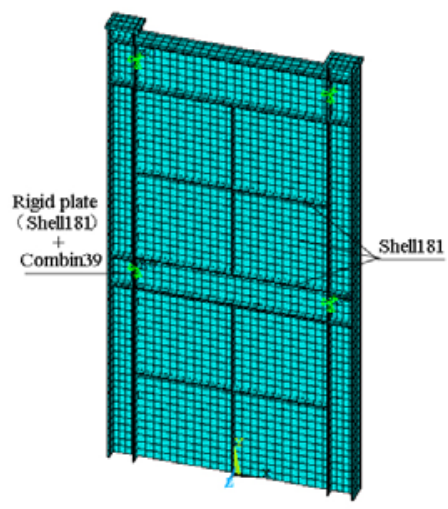

Figure 12. FE Model

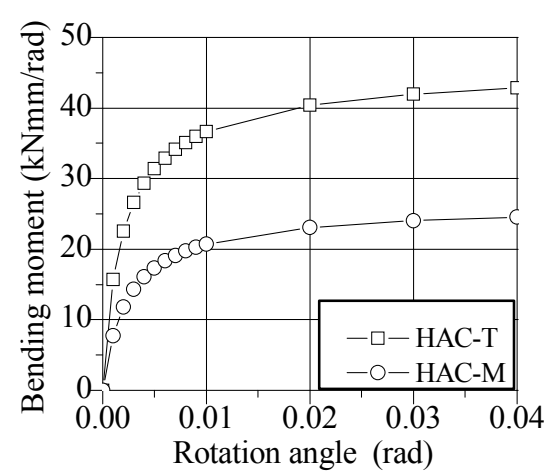

Figure 13. Moment-rotation Relationship

An M- $\theta$ relationship is needed for defining parameters of the Combin39 element. In this paper, Kishi-Chen's three-parameter power function model was used to define the nonlinear moment-rotation relationship. This model is a semi-empirical connection model consisting of three parameters: initial stiffness $R_{k i}$, ultimate moment $M_{u}$ and shape parameter $n$. Equation (2) shows Kishi-Chen's model.

$$
M=\frac{R_{k i} \theta_{r}}{\left[1+\left(\theta_{r} / \theta_{0}\right)^{n}\right]^{1 / n}}
$$

where $\theta_{0}$ is the plastic rotation corresponding to the ultimate moment $\mathrm{M}_{\mathrm{u}} ; \theta_{\mathrm{r}}$ is the rotation of the specimen. The moment-rotation relationships of each connection in the specimens are shown in Figure 13.

\subsection{Model Validation}

Figure 14 shows the simulated hysteretic behaviour of specimen HPP using the FE model. The pinching behaviour of the hysteresis curve in the FE model is smaller than that of the experimental results. Specifically, fluctuation of lateral loading at zero displacement is higher in the FE model as compared with the experimental result. At the elastic-plastic stage, the differences of hysteresis curves between the experiments and Finite Element Analysis became larger. The FE model exhibited a gradual decrease in lateral loading in the inelastic stage of loading. Generally, peak loads achieved in the FE model (i.e. $686.4 \mathrm{kN}$ in push and $696.2 \mathrm{kN}$ in pull) were consistent with those obtained from the experiments (i.e. $684.6 \mathrm{kN}$ in push and $690.0 \mathrm{kN}$ in pull). Figure 15 shows the von Mises stress of specimen HPP at $-42 \mathrm{~mm}$ displacement. Compared to the failure mode in Figure 7(b), the FE model captures the typical characteristics of the specimen. 
The stiffness degradation of the specimens is determined by peaking secant stiffness as specified in section 5.5.3 of the Specifications of Testing Methods for Earthquake Resistant Building (JGJ 101-96). Figure 16 shows the comparison of stiffness degradation obtained from the FE model and experiments. Stiffness in the FE model was higher than that of the experiment at the initial stage of loading (the maximum error was $28 \%$ ). However, stiffness degradation tended to be the same at the final stage of loading (the error was about $5 \%$ ). This was mainly attributed to initial defects in the test. It can be explained as follows. (1) The defect distribution of specimens in the test is different from that in the FE model. The FE model only considers the defects of the infill plate, but without the defects of beams, columns and stiffeners. As the FE model is nearly perfect at the initial stage of loading, it has higher load carrying capacity and stiffness. (2) There is an inevitable initial eccentricity for the applied load in the test. As a result, additional bending and torsion caused by initial eccentricity would reduce the load carrying capacity and stiffness of the SPSW. For the FE model, the column exhibits some degrees of out-of-plane deformation at an advanced stage of loading, which reduced the difference between the test results and FE analysis. (3) Constraints in the FE model are greatly idealized compared with the test specimen. It also can enhance the load carrying capacity and stiffness of specimens. In general, the FE model provides reasonable prediction for the tested specimen.

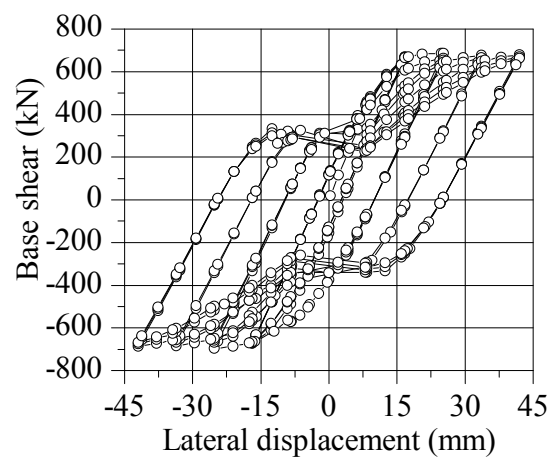

Figure 14. Hysteretic curves of FE

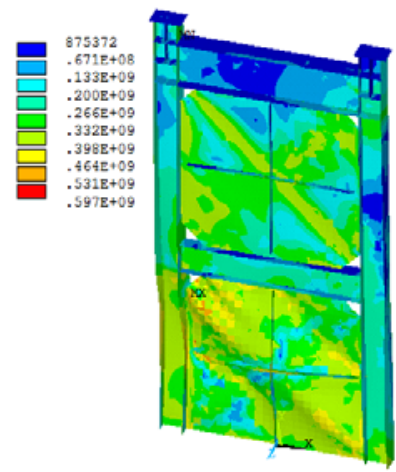

Figure 15. Von Mises Stress at $-42 \mathrm{~mm}$ Displacement

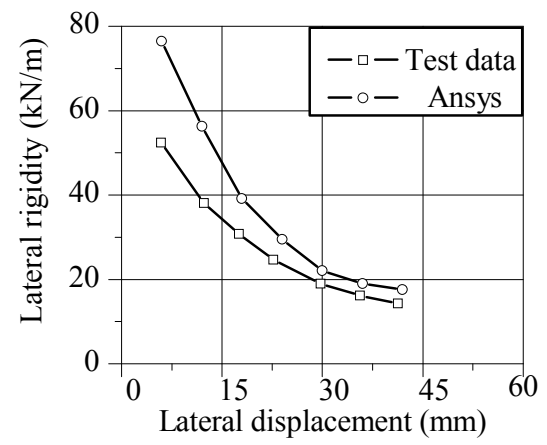

Figure 16. Degeneration of Rigidity

\subsection{Parametric Study}

A parametric study was performed to assess the influence of connection stiffness and stiffeners stiffness on the performance of the new structural system through FE analysis. The tested specimen was set as the basic model (HAC-B). Seven models were divided into two groups, including HAC-SW series and HAC-PR series. The former investigated the effect of stiffener-panel stiffness ratio while the latter aimed to reveal the effect of connection stiffness. FE analysis was conducted for the specimens under monotonic loading. The axial load ratio was the same as that in the experiment. 


\subsubsection{Stiffener-panel stiffness ratio (HAC-SW series)}

In this series, the stiffener-panel stiffness ratio is defined as the ratio of stiffener with unit width to panel. It aimed to compare the effect of the stiffener-panel stiffness ratio on load carrying capacity, ductility and horizontal shear force distribution. Stiffener-panel stiffness ratios considered for the specimens are given in Table 5.

Table 5. HAC-SW Design Parameter

\begin{tabular}{c|cccc}
\hline Specimen & HAC-SW1 & HAC-B & HAC-SW2 & HAC-SW3 \\
\hline Stiffener-panel stiffness ratio & 0 & 12 & 40 & 80 \\
\hline
\end{tabular}

Figure 17 illustrates the load-displacement curves of the specimens in the HAC-SW series. It is obvious that the addition of stiffeners in SPSWs can significantly increase peak load and ductility of SRSFs by comparing HAC-SW1 with the other three specimens. For instance, the peak load of specimen HAC-B increased by 14\% compared with that of specimen HAC-SW1. For SPSW with stiffeners, increasing stiffener-panel stiffness ratio led to a slight enhancement of peak load. The peak load of specimen HAC-SW3 was enhanced by about 3\% when compared with specimen HAC-B. This is attributed to the fact that the stiffeners could restrain out-of-plane deformation of the infill plates efficiently with a certain degree of stiffness. Therefore, continuous increasing of stiffness of the stiffeners could only produce a limited increase to the constraints of SPSW. Considering economic requirements, a stiffener-panel stiffness ratio of 40 is recommended in this paper.

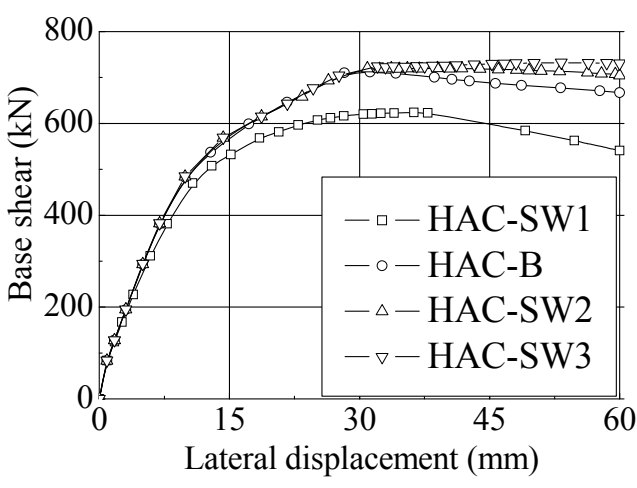

Figure 17. Load-displacement Envelopes of Specimens in HAC-SW

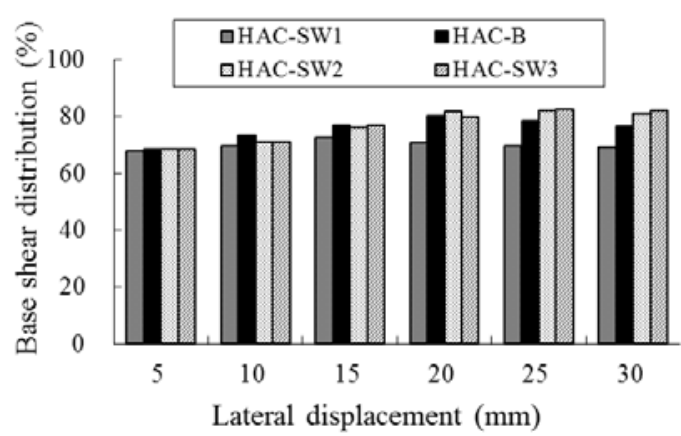

Figure 19. HAC-SW Force Distribution Comparison

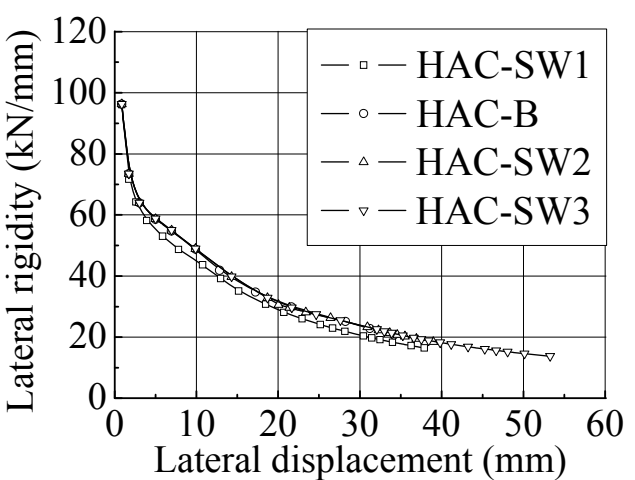

Figure 18. Stiffness Degradation of Specimens in HAC-SW

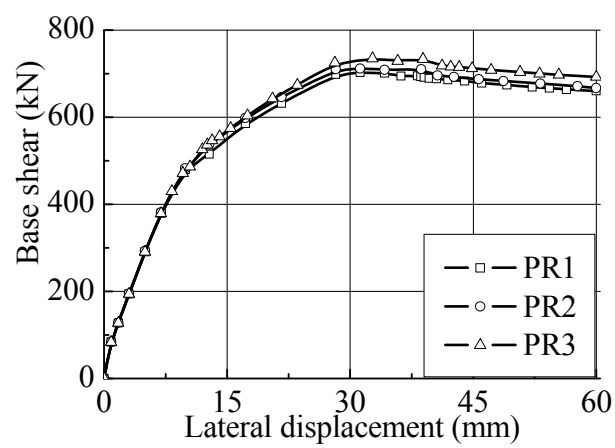

Figure 20. HAC-PR Load-displacement Envelope 
Figure 18 shows the stiffness degradation of the specimens in the HAC-SW series. Force distribution curves of specimens in the HAC-SW series are illustrated in Figure 19. It can be seen that all specimens have similar stiffness degradation through the numerical simulation. At the initial stage of loading, the infill plates made a primary contribution to the lateral shear force plates and this effect was basically identical for the four specimens. It demonstrates that the infill plates are efficient in resisting lateral force at the initial stage of loading. At that time, the infill plates did not buckle and the role of the stiffeners was unobvious. However, the stiffness and the distributed shear force of the non-stiffened SPSW were lower than those of the stiffened SPSW after buckling of the infill plates as lateral displacement increased. Lateral loads were mainly resisted by two portions including the steel frame and connections between the fish plates and the infill plates. Load taken by the frame was limited due to the semi-rigid connections weakening the overall stiffness of the structure. After buckling of the infill plates, stiffeners reduced the load taken by the frame which is beneficial for the requirement of double-protection measures. It has demonstrated that SPSW in the proposed structural system undertakes $70 \%-80 \%$ of overall lateral load.

\subsubsection{Connection stiffness (PR series)}

FE analysis of the PR series aimed to investigate the effect of connection rotational stiffness on the behaviour of SRSF-SPSW. It was achieved through adjusting the bending capacity of the connections. The parameters of the connections are summarized in Table 6 .

Table 6. HAC-PR Design Parameter

\begin{tabular}{c|cccc}
\hline Specimen number & Connections & PR1 & PR2 & PR3 \\
\hline \multirow{2}{*}{ Bending capacity of connections } & HAC-T & $0.20 \mathrm{M}_{\mathrm{p}}$ & $0.40 \mathrm{M}_{\mathrm{p}}$ & infinite \\
& HAC-M & $0.20 \mathrm{M}_{\mathrm{p}}$ & $0.56 \mathrm{M}_{\mathrm{p}}$ & infinite \\
\hline
\end{tabular}

Figure 20 shows the load-displacement curves of specimens in the HAC-PR series. All specimens with different connection stiffness had similar responses in terms of peak lateral load and stiffness. In the plastic stage, increasing connection stiffness enhanced the peak lateral load of the specimens. However, the magnitude of the increase ratio was not significant. The peak load of specimen HAC-PR 2 increased by $5 \%$ as compared with that of specimen HAC-PR 1 . Therefore, the influence of beam-column connections on lateral load capacity is limited. This is mainly attributed to the large flexibility factor of the column. For a definition of flexibility factor $\omega_{\mathrm{t}}$ of a column one can refer to $\mathrm{Qu}$ and Bruneau [8]. It also specifies that the $\omega_{\mathrm{t}}$ is no larger than 2.5. In this study, the flexibility factor of specimens HAC and HPP were equal to 2.69 which is larger than 2.5. As shown in Figure 7(a), W-column and E-column show obvious curved concave deformation.

In order to further study the influence of the beam-column connection characteristics on the behaviour of the SRSF-SPSW system, the first storey of specimen HAC was modelled as shown in Figure 21(a). It can be equivalent to the model shown in Figure 21(b). The size of SPSW was $\mathrm{L} \times \mathrm{H}$ ( $\mathrm{L}$ is the height of model, $\mathrm{H}$ is the width of model and the base size is $1200 \mathrm{~mm} \times 1200 \mathrm{~mm}$ ). The bottom of the column was hinged to the foundation. A beam is considered as a rigid beam by using the method of DOF coupling, thereby removing the influence of the flexible boundary beam. In order to improve the efficiency of analysis, the Beam188 element was used to simulate the boundary members while the Shell181 element was adopted to simulate the infill plate. Using the ideal elastic-plastic model as stress-strain curve, setting the yield strength of steel as $235 \mathrm{~N} / \mathrm{mm}^{2}$, the modulus of elasticity as $2.1 \times 10^{5} \mathrm{~N} / \mathrm{mm}^{2}$ and $0.1 \%$ of the out-of-plane buckling deformation as the initial imperfection of model specimen, the finite element specimen is shown in Figure 21(c). 


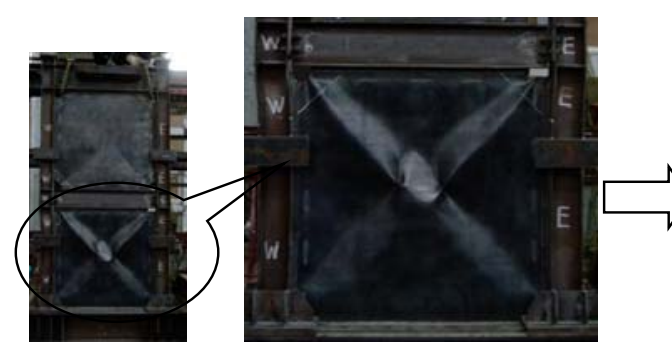

(a)

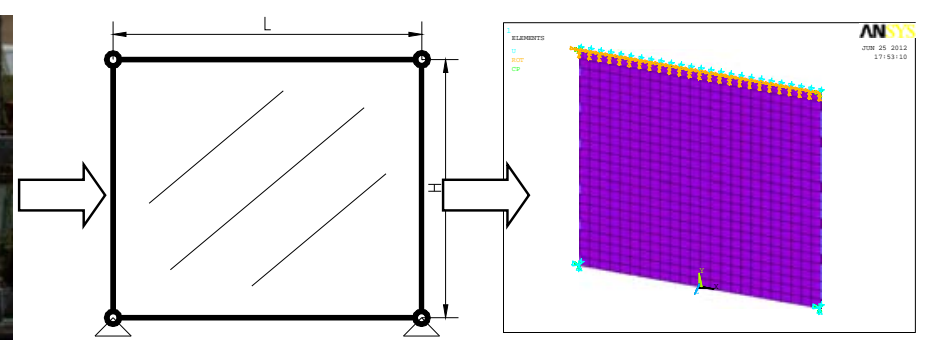

(b)

(c)

Figure 21. Establishment of Finite Element Model

The relationship between the stress uniformity ratio $\gamma=\mathrm{S}_{\text {average }} / \mathrm{S}_{\max }$ and the flexibility factor (i.e.,

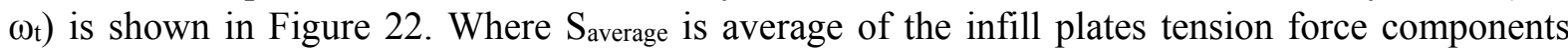
parallel with the beam; $\mathrm{S}_{\max }$ is maximum of the web tension force components parallel with the beam. As shown on that curve, for smaller values of $\omega_{t}$ (e.g., in the range $0 \leqslant \omega_{t} \leqslant 1$ ), for which the SPSW have relatively stiff columns, the stress uniformity ratio approximately equals 1 (which physically means that the maximum stress is close to the average stress), indicating development of a uniform infill plates tension field. However, with increases in the flexibility factor, the stress uniformity ratio decreases, indicating formation of a less uniform infill plates tension field in SPSW having more flexible columns.

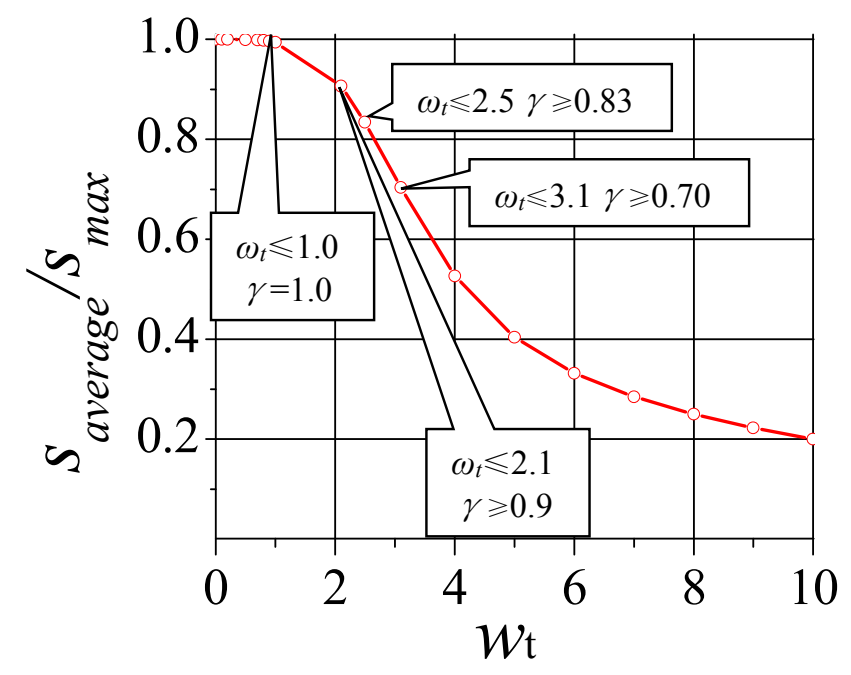

Figure 22. Relationship between $S_{\text {average }} / S_{\max }$ and $\omega_{t}$

The main influencing factors on the load carrying capacity of the tested specimen are column flexibility and ratio of SPSW height to thickness. This study set the ratio of height to thickness at 100,200 , and 400 , and the column flexibility $\omega_{\mathrm{t}}$ as $1.0,2.1,2.5$, and 3.1 , which respectively correspond to $1.00,0.90,0.83$, and 0.70 , setting four levels of stress uniformity coefficient $\gamma$ as shown in Figure 22. The orthogonal test table is summarized in Table 7.

Table 7. The Orthogonal Test Table

\begin{tabular}{|c|c|c|c|c|c|}
\hline \multicolumn{3}{|c|}{ Factors } & \multicolumn{3}{|c|}{ Specimen number } \\
\hline \multirow{4}{*}{ Column flexibility } & $\mathrm{C} 1$ & 1.0 & $\mathrm{C} 1-\mathrm{W} 1$ & C1-W2 & $\mathrm{C} 1-\mathrm{W} 3$ \\
\hline & $\mathrm{C} 2$ & 2.1 & $\mathrm{C} 2-\mathrm{W} 1$ & $\mathrm{C} 2-\mathrm{W} 2$ & $\mathrm{C} 2-\mathrm{W} 3$ \\
\hline & $\mathrm{C} 3$ & 2.5 & $\mathrm{C} 3-\mathrm{W} 1$ & C3-W2 & $\mathrm{C} 3-\mathrm{W} 3$ \\
\hline & $\mathrm{C} 4$ & 3.1 & $\mathrm{C} 4-\mathrm{W} 1$ & C4-W2 & C4-W3 \\
\hline \multicolumn{2}{|c|}{ Ratio of height to thickness } & $\left(\mathrm{H} / \mathrm{t}_{\mathrm{w}}\right)$ & $\begin{array}{l}100 \\
W 1\end{array}$ & $\begin{array}{l}200 \\
W 2\end{array}$ & $\begin{array}{l}400 \\
\mathrm{~W} 3\end{array}$ \\
\hline
\end{tabular}


Peak lateral loads of specimens could be obtained by calculating the conditions of different column flexibility and SPSW height to thickness ratio as shown in Table 8. Theoretical shear strength of the infill plates (the infill plates under complete shear mechanism) can be computed by $V_{p u}=f_{v} t_{w} L$. Based on these, this paper compares the enhancement effect, of different connection types, i.e., super action of frame, which could greatly influence the column flexibility, in the following paragraphs.

Table 8 compares the load carrying capacities of specimens with different connection stiffness. Generally, the load carrying capacity of a specimen increases as the stiffness of connections increases. Also, the influence of connection stiffness on load carrying capacity is related to the stiffness of column and thickness of the infill plate. This influence is enlarged when increasing the stiffness of the column and reducing the thickness of the infill plate. As a result, the load carrying capacity of a specimen with a strong column-weak plate is highly affected by connection stiffness. Among all the specimens, specimen C1-W3 exhibited the maximum response to connection stiffness. Specifically, the load carrying capacity of specimen C1-W3 increased by $42.2 \%$ when the connection was changed from pin to rigid. The load carrying capacity of specimen C1-W3 with rigid connection was $13.8 \%$ higher than that of specimens with semi-rigid connections. For the specimens with a flexibility coefficient of column of 2.5 (e.g. for series C3), the load carrying capacity was enhanced by about $10 \%$ when changing pinned connections to rigid connections. The load carrying capacity of specimens with semi-rigid connections was $3.0 \%$ higher than that of specimens with rigid connections. When replacing pinned connections with rigid connections for the specimens with the columns which flexibility coefficient is 2.1 (e.g. in series C2), the load carrying capacity increased by $23.5 \%$. The load carrying capacity of specimens with semi-rigid connections was similar to that of specimens with rigid connections. Due to the super action of frames in SRSF-SPSW, the load carrying capacity of specimens with semi-rigid connections was higher than the shear strength of the infill plate. Thus, SRSF-SPSW can be designed according to the shear strength of the infill plate while super action is considered as a safety factor. Specimens in series C-RP were stiffened by specimen HAC-SW2. Table 8 only shows the results of specimens in series W3. Due to the stiffening effect of the infill plate, the influence of connection stiffness on load carrying capacity decreased for the specimens in series C-PR. The load carrying capacity of specimens with rigid connections was about $30 \%$ higher than that with pinned connections and about $8 \%$ higher than those with semi-rigid connections. This indicates that stiffeners prevent the buckling of infill plates, which weakens the adverse influence of flexible connection on the frame load carrying capacity.

Table 9 compares the relationship between the shear distributions of the infill plate with different types of connections. For the specimens with ratio of height to thickness of 400 (e.g. series W3), shear forces taken by infill walls were almost the same regardless of the flexibility of column and connection stiffness. With the increase of beam-column connection rotational stiffness, the load carrying capacity of the steel frame is slightly increased. For the unstiffened thin SPSW (e.g. for series P-PR), shear force taken by infill plates is seldom affected by connection stiffness when the flexibility of columns is no larger than 2.5 . When the column is relatively flexible, connection stiffness has a certain influence on the shear force taken by infill plates. For the stiffened thin SPSW (e.g. for series C-PR), shear forces taken by infill plates are almost the same, around $460 \mathrm{kN}$. However, shear forces taken by the whole system increase as connection stiffness increases. It indicates that forces taken by columns is proportional to the connection stiffness increases. Meanwhile, setting the stiffener could improve the tension field for shear resistance. Shear force taken by infill plates in the C-PR series specimens was close to the shear resistant capacity $\mathrm{V}_{\mathrm{pu}}$ of the infill plates under complete shear as shown in Table 8. There is a significant "lining" effect in the corner of the stiffened steel plates and thick plates, which strengthens the beam-column connections. Thus, even if a simple beam-column connection is used in a steel frame, it could 
contribute to resist bending. Because the effect improvement is limited, it could be considered as a factor of safety.

Table 8. ANSYS Load Carrying Capacity Calculation (unit: $\mathrm{kN}$ )

\begin{tabular}{cccccccccccc}
\hline Category & Specimen & PR 1 & PR 2 & PR 3 & $\begin{array}{c}\text { PR3 } \\
\text { /PR1 }\end{array}$ & $\begin{array}{c}\text { PR2 } \\
\text { /PR1 }\end{array}$ & $\begin{array}{c}\text { PR3 } \\
\text { /PR2 }\end{array}$ & Vpu & $\begin{array}{c}\text { PR1 } \\
\text { /Vpu }\end{array}$ & $\begin{array}{c}\text { PR2 } \\
\text { /Vpu }\end{array}$ & $\begin{array}{c}\text { PR3 } \\
\text { / Vpu }\end{array}$ \\
\hline \multirow{6}{6}{ P-PR } & & & & & & \\
& C1-W1 & 1975.5 & 2002.7 & 2117.8 & 1.072 & 1.014 & 1.057 & 1952.5 & 1.012 & 1.026 & 1.085 \\
& C1-W2 & 930.64 & 1027.1 & 1078.9 & 1.159 & 1.104 & 1.050 & 976.28 & 0.953 & 1.052 & 1.105 \\
& C1-W3 & 464.89 & 581.00 & 660.94 & 1.422 & 1.250 & 1.138 & 488.14 & 0.952 & 1.190 & 1.354 \\
& C2-W1 & 1972.6 & 1998.0 & 2097.53 & 1.063 & 1.013 & 1.050 & 1952.5 & 1.010 & 1.023 & 1.074 \\
& C2-W2 & 906.94 & 1010.6 & 1024.73 & 1.130 & 1.114 & 1.014 & 976.28 & 0.929 & 1.035 & 1.050 \\
& C2-W3 & 462.80 & 558.74 & 571.50 & 1.235 & 1.207 & 1.023 & 488.14 & 0.948 & 1.145 & 1.171 \\
& C3-W1 & 1967.22 & 1992.4 & 2052.2 & 1.043 & 1.013 & 1.030 & 1952.5 & 1.008 & 1.020 & 1.051 \\
& C3-W2 & 882.38 & 955.76 & 970.44 & 1.100 & 1.083 & 1.015 & 976.28 & 0.904 & 0.979 & 0.994 \\
& C3-W3 & 454.46 & 489.67 & 490.07 & 1.078 & 1.077 & 1.001 & 488.14 & 0.931 & 1.003 & 1.004 \\
& C4-W1 & 1959.87 & 1973.97 & 1988.96 & 1.015 & 1.007 & 1.008 & 1952.5 & 1.004 & 1.011 & 1.019 \\
& C4-W2 & 812.97 & 846.35 & 857.43 & 1.055 & 1.041 & 1.013 & 976.28 & 0.833 & 0.867 & 0.878 \\
& C4-W3 & 405.91 & 421.74 & 420.69 & 1.036 & 1.039 & 0.998 & 488.14 & 0.832 & 0.864 & 0.862 \\
\hline \multirow{6}{*}{ C-PR } & C1-W3 & 499.25 & 615.81 & 665.05 & 1.332 & 1.233 & 1.080 & 488.14 & 1.023 & 1.262 & 1.362 \\
& C2-W3 & 496.91 & 599.65 & 618.87 & 1.245 & 1.207 & 1.032 & 488.14 & 1.018 & 1.228 & 1.268 \\
& C3-W3 & 495.04 & 547.59 & 550.70 & 1.112 & 1.106 & 1.006 & 488.14 & 1.014 & 1.122 & 1.128 \\
& C4-W3 & 486.55 & 499.56 & 500.43 & 1.029 & 1.027 & 1.002 & 488.14 & 0.997 & 1.023 & 1.025 \\
\hline
\end{tabular}

Note: P and C halves are SPSW with and without stiffeners, respectively.

Table 9 The shear distribution of infill plate (unit: $\mathrm{kN}$ )

\begin{tabular}{|c|c|c|c|c|c|c|c|c|c|c|}
\hline \multirow{2}{*}{ Category } & \multirow{2}{*}{ Specimen } & \multicolumn{3}{|c|}{ PR1 } & \multicolumn{3}{|c|}{ PR2 } & \multicolumn{3}{|c|}{ PR3 } \\
\hline & & $\mathrm{V}_{\mathrm{p}}$ & V & $\mathrm{V}_{\mathrm{p}} / \mathrm{V}$ & $\mathrm{V}_{\mathrm{p}}$ & $\mathrm{V}$ & $\mathrm{V}_{\mathrm{p}} / \mathrm{V}$ & $\mathrm{V}_{\mathrm{p}}$ & V & $\mathrm{V}_{\mathrm{p}} / \mathrm{V}$ \\
\hline \multirow{6}{*}{ P-PR } & $\mathrm{C} 1-\mathrm{W} 3$ & 437.01 & 464.89 & 0.940 & 437.06 & 581.00 & 0.752 & 436.87 & 660.94 & 0.661 \\
\hline & C2-W1 & 1861.10 & 1972.63 & 0.948 & 1867.60 & 1998.05 & 0.935 & 1870.60 & 2097.53 & 0.887 \\
\hline & $\mathrm{C} 2-\mathrm{W} 2$ & 865.94 & 906.94 & 0.962 & 872.81 & 1010.69 & 0.865 & 874.34 & 1024.73 & 0.845 \\
\hline & $\mathrm{C} 2-\mathrm{W} 3$ & 429.22 & 462.80 & 0.937 & 432.70 & 558.74 & 0.774 & 433.85 & 571.50 & 0.751 \\
\hline & C3-W3 & 422.21 & 454.46 & 0.932 & 423.08 & 489.67 & 0.864 & 423.50 & 490.07 & 0.862 \\
\hline & C4-W3 & 395.91 & 405.91 & 0.975 & 405.38 & 421.74 & 0.961 & 405.44 & 420.69 & 0.963 \\
\hline \multirow{4}{*}{ C-PR } & $\mathrm{C} 1-\mathrm{W} 3$ & 463.32 & 499.25 & 0.928 & 463.36 & 615.81 & 0.752 & 463.40 & 665.05 & 0.696 \\
\hline & $\mathrm{C} 2-\mathrm{W} 3$ & 462.34 & 496.91 & 0.930 & 462.42 & 599.65 & 0.771 & 462.88 & 618.87 & 0.748 \\
\hline & C3-W3 & 461.54 & 495.04 & 0.932 & 461.52 & 547.59 & 0.843 & 461.90 & 550.70 & 0.839 \\
\hline & C4-W3 & 461.25 & 486.55 & 0.948 & 461.3 & 499.56 & 0.923 & 461.6 & 500.43 & 0.920 \\
\hline
\end{tabular}

For specimens with the same columns and infill plates but with limited flexibility factor (e.g. series $\mathrm{C} 1, \mathrm{C} 2$ and $\mathrm{C} 3$ ), the load carrying capacity of the structural system increases as connection stiffness increases under various flexibility factors. It indicates that enhancement of the load carrying capacity of the structural system results from increasing connection characteristics. Thus, connection characteristics could significantly influence the shear force taken by the frame. This means that the improvement of the structural load carrying capacity results from the contribution of the frame, which forms the second defence line for earthquake-resistant building.

\section{CONCLUSIONS}

This paper introduces a new type of structural system consisting of SRSF-SPSW. The seismic behaviour of this new structural system was estimated through experimental study and finite element analysis. Based on experimental results and parametric study, the following conclusions can be drawn. 
(1) Setting of crossed stiffeners in SPSW with a stiffener-panel stiffness ratio of 12 increases stiffness, ductility, and peak lateral load of SRSF-SPSW by $6 \%, 17 \%$, and $18 \%$, respectively. It is attributed to the stiffeners reducing the height-thickness ratio of the plates, which improves the loading condition of the infill plates as well as delaying the buckling of steel panels.

(2) Incorporating stiffeners in SPSW increases the buckling load of thin steel plates due to its restraining effect in out-of-plane deformation. The stiffeners also reduce the concavity of columns, which leads to uniform distribution of forces between two floors.

(3) The use of thick SPSWs can be avoided through proper stiffener setting. Increasing the stiffness of the stiffeners can enhance the initial stiffness and peak lateral load of SRSF-SPSW and improve the overall behaviour of the specimen. The stiffener-panel stiffness ratio is recommended to be around 40 .

(4) The influence of connection stiffness on the load carrying capacity of the structural system is related to the stiffness of columns and thickness of infill plates. This influence is enlarged with increasing stiffness of columns and reducing thickness of infill plates. The load carrying capacity of a structural system with strong column-weak plate is significantly affected by connection stiffness and is increased by $42.2 \%$ when the connection is changed from pinned to rigid. For structural systems with weak columns (e.g. flexibility coefficient of columns is smaller than 2.5), the load carrying capacity is enhanced by less than $10 \%$ when changing pinned connections to rigid connections.

\section{ACKNOWLEDGMENTS}

The authors are grateful to the financial support from NSF (Project No: 51408461). The authors would like to thank the technical assistance provided by Structural Engineering Research Laboratory at Xi'an University of Architecture and Technology.

\section{REFERENCES}

[1] Thorburn, L.J., Kulak, G.L. and Montgomery, C.J., "Analysis of Steel Plate Shear Walls", Structural Engineering Report.No.107. Department of Civil Engineering, University of Alberta, Canada, 1983.

[2] Lubell, A.S. and Prion, H.G.L., "Unstiffened Steel Plate Shear Walls Performance Under Cyclic Load", Journal of Structural Engineering, 1983, Vol. 126, No. 4, pp. 453-460.

[3] Chen, G.D. and Guo, Y.L., "An Cyclic Test of Steel Plate Shear Walls", Journal of Building Structures, 2004, Vol. 25, No. 2, pp. 19-26 (in Chinese).

[4] Wang, Y.C., "Experiment and Theory Study of Bearing Capacity of Steel Plate Shear Walls on compound load action", PhD, Xi'an University of Architecture \& Technology, 2011 (in Chinese).

[5] Lin, Y.C. and Tsai, K.C., "Seismic Responses of Steel Plate Shear Walls Constructed with Restrainer" Report NCREE-04-015, National Center for Research on Earthquake engineering, Taipei, Taiwan, R.O.C., (in Chinese).

[6] Park, H., Kwack, J., Jeon, S., Kim, W. and Choi, I., "Framed Steel Plate Wall Behavior under Cyclic Lateral Loading", Journal of Structural Engineering, ASCE, 2007, Vol. 133, No. 3, pp. 378-388.

[7] Tsai, K.C. and Li, C.H., "Cyclic Tests of Four Two-storey Narrow Steel Plate Shear Walls-Part 1 Analytical Studies and Specimen Design", Earthquake Engineering \& Structural Dynamics, 2010, Vol. 39, pp. 775-799. 
[8] Qu, B. and Bruneau, M., "Testing of Full-scale Two-storey Steel Plate Shear Wall with Reduced Beam Section Connections and Composite Floors", Journal of Structural Engineering, ASCE, 2008, Vol. 134, No. 3, pp. 364-373.

[9] Habashi, H.R. and Alinia, M.M., "Characteristics of the Wall-frame Interaction in Steel Plate Shear Walls." Journal of Constructional Steel Research, 2010, Vol. 66, No. 2, pp. 150-158.

[10] Kurata, M., Leon, R.T., Desroches, R. and Nakashima, M., "Steel Plate Shear Wall with Tension-bracing for Seismic Rehabilitation of Steel Frames", Journal of Constructional Steel Research, 2012, Vol. 71, pp. 92-103.

[11] Zhang, X.Q. and Guo, Y.L., "Behavior of Steel Plate Shear Walls with Pre-compression Adjacent Frame Columns", Thin-Walled Structures, 2014, Vol. 77, pp. 17-25.

[12] Bhowmick, A.K., Grondin, G.Y. and Driver, R.G., "Nonlinear Seismic Analysis of Perforated Steel Plate Shear Walls", Journal of Constructional Steel Research, 2014, Vol. 94, pp. 103-113.

[13] Alinia, M.M. and Dastfan, M., "Cyclic Behaviour, Deformability and Rigidity of Stiffened Steel Shear Panels", Journal of Constructional Steel Research, 2007, Vol. 63, No. 4, pp. 554-563.

[14] Alavi, E. and Nateghi, F., "Experimental Study on Diagonally Stiffened Steel Plate Shear Walls with Central Perforation", Journal of Constructional Steel Research, 2013, Vol. 89, pp. 9-20.

[15] Nie, J.G., Zhu, L., Fan, J.S. and Mo, Y.L., "Lateral Resistance Capacity of Stiffened Steel Plate Shear Walls", Thin-Walled Structures, 2013, Vol. 67, No. 3, pp. 155-167.

[16] Azizinamini, A. and Radziminski, J.B., "Static and Cyclic Performance of Semi-rigid Steel Beam-column Connections", Journal of Structural Engineering, ASCE, 1989, Vol. 115, No. 12, pp. 2979-2999.

[17] Elnashai, A.S. and Elghazouli, A.Y., "Seismic Behavior of Semirigid Steel Frames", Journal of Constructional Steel Research, 1994, Vol. 29, No. 1, pp. 149-174.

[18] Kishi, N., Chen, W.F. and Goto, Y., "Effective Length Factor of Columns in Semi-rigid and Unbraced Frames", Journal of Structural Engineering, ASCE, 1997, Vol. 123, No. 3, pp. 313-320.

[19] Bernuzzi, C., Zandonini, R. and Zanon, P., "Experimental Analysis and Modeling of Semi-rigid', 1996, Vol. 38, No. 2, pp. 95-123.

[20] Yu, J.G., Hao, J.P., Zhang, W.Q., Zhong, W.H. and Xie, Q., "Stability Analysis for Semi-rigid Jointed and Braced Steel Frames", World Earthquake Engineering, 2010, Vol. 26, No. 3, pp. 101-108 (in Chinese).

[21] Xie, Q., Hao, J.P. and Yu, J.G., "Study on Semi-rigid Frame with Steel Palte Shear Wall", Beijing, Proceeding of the Eleventh International Symposium on Structural Engineering, 2010, pp. 1917-1923.

[22] Caccese, V., Elgaaly, M. and Chen, R., "Experimental Study of Thin Steel-Plate Shear Walls Under Cyclic Load”, Journal of Structural Engineering, 1993, Vol. 119, No. 2, pp. 573-587.

[23] Kulak, C.L., Laurte Kennedy, D.J. and Driver, R.G., "Discussion of Experimental Study on Thin Steel Plate Shear Watts under Cyclic Load by Caccese, V., Elgaaly, M., and Chen, R.", Journal of Structural Engineering, 1994, Vol. 120, No.10, pp. 3072-3073.

[24] Xie, M., "Behavior of Steel Shear Wall Panels and Frame-Wall Systems", Bethlehem, Pennsylvania, Lehigh University, 1995.

[25] Alinia, M.M. and Dastfan, M., "Behaviour of Thin Steel Plate Shear Walls Regarding frame Members ", Journal of Constructional Steel research, 2006, Vol. 62, No. 7, pp. 730-738. 
[26] GB/T228-2002, "Metallic Materials-Tensile Testing at Ambient Temperature", 2009, Beijing, China Standard Press (in Chinese).

[27] GB/T 2975-1998, "Steel and Steel Products-Location and Preparation of Test Pieces for Mechanical Testing”, 2009, Beijing, China Standard Press (in Chinese).

[28] JGJ 101-96, "Specification of Testing Methods for Earthquake Resistant Building", 1997, Beijing, China Architecture and Building Press (in Chinese). 